\title{
Analisis Kinerja Dewan Pengawas Syariah Dalam Mengawasi Bank Syariah
}

\author{
Ana Nurwakhidah \\ Universitas Islam Raden Rahmat Malang \\ anan.jameelah@gmail.com
}

\section{Article Info}

Article history:

Received Oct19th, 2020

Revised Oct 30th, 2020

Accepted Nov 5th, 2020

\section{Keyword:}

Analysis,

Sharia Supervisory Board,

Islamic Bank.

\begin{abstract}
This research is motivated by the performance of the Sharia Supervisory Board (DPS) in overseeing Sharia Banks, due to the large number of branches and cash offices owned by Islamic banks, while the number of DPS in overseeing Islamic Banks is very limited.

The results of the function of supervising products had been carried out well. Supervision of published product practices, DPS supervises from the initial product being published until the product is operational, such as making an opinion until the product is implemented. While the effectiveness is fairly effective, because DPS is consistent in maintaining sharia compliance and the established rules are supported by an area of supervision that can still be reached because it only has 2 branch offices and 10 cash offices. Nevertheless, DPS in BPRS Bumi Rinjani Kepanjen still has weaknesses. This weakness is essentially not in violation of existing regulations. It's just an important note that existence still needs to be improved, and developed.
\end{abstract}

Copyright@2020 Program Studi Ekonomi Syariah Universitas Yudharta Pasuruan All rights reserved.

DOI: https://doi.org/10.35891/ml.v12i1.2381

\section{Corresponding Author:}

Ana Nurwakhidah,

Lecturer at Raden Rahmat Islamic University Malang

Email: anan.jameelah@gmail.com 


\section{A. Pendahuluan}

Bank syariah di Indonesia berkembang pesat seiring dengan berjalannya waktu. Per Juni 2015, industri perbankan syariah terdiri dari 12 Bank Umum Syariah, 22 Unit Usaha Syariah yang dimiliki oleh Bank Umum Konvensional dan 162 BPRS dengan total aset sebesar Rp. 273,494 Triliun dengan pangsa pasar 4,61\%. Khusus untuk wilayah Provinsi DKI Jakarta, total aset gross, pembiayaan, dan Dana Pihak Ketiga (BUS dan UUS) masing-masing sebesar Rp. 201,397 Triliun, Rp. 85,410 Triliun dan Rp. 110,509 Triliun (Otoritas Jasa Keuangan, 2019).

Perbedaan utama dari bank konvensional dan bank syariah selain dari pelayanannya juga dari istilah bunga dan bagi hasil yang dipakai di masing-masing bank. Dalam bank syariah tidak ada bunga melainkan bagi hasil, dimana ada pembagian keuntungan sesuai dengan presentase yang disepakati. Banyak peraturan di perbankan syariah dibandingkan dengan bank konvensional. Di bank konvesional hanya ada satu kesepakatan yang diberi nama kredit. Sedangkan di perbankan syariah ada berbagai jenis kesepakatan atau biasa di sebut "akad". Setiap produk yang di tawarkan memiliki akad yang berbeda (Ismanto \& Laksono, 2020).

Ada suatu dewan khusus yang bertugas untuk mengawasi dan memastikan Bank Syariah mematuhi aturan syariah dalam pelaksanaan produk, yaitu Dewan Pengawas Syariah. Dewan Pengawas Syariah adalah suatu dewan yang didirikan untuk mengawasi kegiatan operasi bank Islam sehingga tidak sampai melanggar prinsip syariah atau senantiasa sesuai dengan prinsip muamalah dalam Islam. Pada bank konvensional tidak ada badan yang bertugas layaknya seorang Dewan Pengawas Syariah. Inilah letak berbedan yang paling unik. Dimana dalam mengawasi, untuk penerapan prinsipnya. Ada badan yang mengawasi (Rosyidah et al., 2019).

Indonesia memiliki Unit Usaha Syariah dan Bank Umum Syariah yang setiap tahunnya selalu berkembang dan bertambah. Yang menyebar di seluruh Indonesia. Dengan bertambah banyaknya jumlah BUS dan UUS yang ada di Indonesia menyebabkan bertambah luas dan besar cakupan dari pengawas syariah (Nizar, 2016).

Berdasarkan data statistik Otoritas Jasa Keuangan menunjukkan Bank Syariah Mandiri adalah bank dengan jumlah kantor cabang dan anak cabang syariah yang terbanyak. Dengan Kantor Pusat Operasional 130 kantor, kantor cabang pembantu 424 kantor dan Kantor kas sebanyak 52 kantor. Yang dapat dipastikan menyebar di seluruh pelosok Indonesia. Setiap Bank Umum Syariah atau Bank Konvensional yang memiliki Unit Usaha Syariah harus memiliki setidaknya 2-5 Orang sebagai anggota Dewan Pengawas Syariah. Sedangkan untuk Bank Pembiayaan Rakyat Syariah setidaknya memiliki 1-3 orang anggota DPS. Dengan jumlah DPS paling banyak 5 anggota. Dapatkah mengawasi, dan menjalankan fungsi dan tugasnya, terhadap bank tersebut. Tidak hanya mengawasi produk-produknya melaikan juga pada pelaksanaannya. Pada kenyataanya, sistem ataupun prinsip yang diterapkan di perbankan syariah sesuai dengan syariah. Tetapi dalam praktek dan pelaksanaannya masih belum mendekati prinsip syariah (Kurrohman, 2017). 
Bank Pembiayaan Rakyat Syariah (BPRS) Bumi Rinjani Kepanjen yang merupakan kantor pusat dengan mempunyai 1 kantor cabang dan 10 kantor kas. Dimana kantor cabang dan kantor kas masih dapat dijangkau oleh Dewan Pengawas Syariah. Melihat jumlah kantor cabang dan kantor kas BPRS Bumi Rinjani Kepanjen masih sangat mungkin bisa dijangkau, berbeda dengan bank-bank besar yang sudah menasional yang memiliki kantor pusat di Jakarta atau kota besar sementara kantor cabang yang menyebar diseluruh Indonesia. Yang hal ini menimbulkan pertanyaan peneliti, bagaimana pengawasan syariah yang terjadi di bank-bank yang sudah berskala nasional tersebut.

Peneliti menganalisis di BPRS Bumi Rinjani Kepanjen yang mana Dewan Pengawas Syariah yang beranggotakan dua orang sudah dirasa cukup dan mampu melaksanakan tugas dan kewajibannya. Namun tidak bisa menjadi tolak ukur, karena dalam konteks kenyataan atau realita yang berbeda dengan itu peneliti mengadakan Penelitian dengan judul Analisis Kinerja Dewan Pengawas Syariah dalam mengawasi Bank Syariah (Studi kasus: di BPRS Bumi Rinjani Kepanjen.

Adapun rumusan masalah penelitian ini diantaranya: Bagaimana fungsi Dewan Pengawas Syariah dalam pengawasan produk-produk di BPRS Bumi Rinjani Kepanjen?, Bagaimana pengawasan praktek produk yang diterbitkan oleh BPRS Bumi Rinjani Kepanjen?, Bagaimana efektivitas pengawasan Dewan Pengawas Syariah terhadap seluruh produk perbankan yang ada di BPRS Bumi Rinjani Kepanjen?. Sedangkan tujuan penelitian ini adalah: Untuk mengetahui posisi Dewan Pengawas Syariah dalam pengawasan produk-produk di BPRS Bumi Rinjani Kepanjen, Untuk mengetahui pengawasan praktek produk yang diterbitkan oleh BPRS Bumi Rinjani Kepanjen, Untuk mengetahui Seberapa efektifnya pengawasan Dewan Pengawas Syariah terhadap seluruh produk perbankan yang ada di BPRS Bumi Rinjani Kepanjen.

\section{B. Kajian Teori}

\section{Kinerja}

Menurut Oktiani et al., (2019), kinerja karyawan merupakan tingkatan dimana para karyawan mencapai persyaratan-persyaratan pekerjaan. Menurut Robbins and Judge (2008) kinerja diartikan sebagai fungsi dan interaksi antara kemampuan (ability) motivasi (motivation) dan kesempatan (opportunity), atau kinerja.

Nawangsari and Ika Nugroho (2019) menyampaikan ada enam kriteria dasar atau dimensi untuk mengukur kinerja antara lain:

a. Kualitas pekerjaan (quality) adalah nillai dimana proses atau hasil ketelitian dalam melaksanakan pekerjaan.

b. Kuantitas pekerjaan (quantity), jumlah pekejaan yang dihasilkan atau dilakukan, dan ditandakan seperti nilai uang, jumlah barang, atau jumlah kegiatan yang telah dikerjakan atau yang terlaksana.

c. Ketepatan waktu (timeliness) merupakan nilai dimana suatu pekerjaan dapat dilaksanakan sesuai dengan waktu yang telah ditetapkan, atau pada waktu yang ditentukan. 
..:: Malia: Jurnal Ekonomi Islam Vol. 12 No. 1, Desember 2020 ::..

d. Efektifitas biaya (cost-efferctiveness) merupakan terkait dengan penggunaan sumber-sumber organisasi dalam mendapatkan atau memperoleh hasil atau pengurangan pemborosan dalam menggunakan sumber-sumber organisasi.

e. Kebutuhan pengawasan (need for supervision) dimana pegawai dapat menyelesaikan pekerjaan atau fungsi-fungsi pekerjaan tanpa asistensi pemimpin atau intervensi pengawasan pimpinan.

f. Kemampuan diri (interpersonal impact) terkait dengan kemampuan individu dalam meningkatkan perasaan harga diri, keinginan baik dan kerjasama di antara sesama pekerja dan anak buah.

\section{Dewan Pengawas Syariah}

Dewan Pengawas Syariah adalah dewan yang dibentuk oleh Majelis Ulama Indonesia (MUI) yang bertugas dan memiliki kewenangan untuk menetapkan fatwa tentang produk dan jasa dalam kewenangan untuk menetapakan fatea tentang produk dan jasa dalam kegiatan usaha bank yang melaksanakan kegiatan usaha berdasarkan prinsip-prinsip syariah. Dewan Pengawas Syariah terdiri daro pakar-pakar syariah yang mengawasi aktivitas dan operasional unstitusi financial untuk memastikan kepatuhan terhadap prinsip-prinsip syariah (Heteronom, 2017).

Menurut Shehata mendefinisikan Dewan Pengawas Syariah sebagai:

... a process of review, investigation and analysis of all works, actions and behaviors that are conducted by individuals, groups, institutions and business units to ensure their compliance with Shari'a. To do so, the Shari'a Supervisory Board (SSB) uses appropriate tools and approaches to detect errors and correct them immediately and submit its reports to the relevant parties including its opinion, recommendations and guidance for improvement (Garas and Pierce, 2010).

Sedangkan Atteya mendefinisikan sebagai:

... the initial efforts of IFI's founders and stakeholders which are derived by their desire to lead the IFI and control its activities according to their zeal towards the IFI and their ability in detecting errors and correcting them with the assistance of qualified individuals (Nathan Garas, 2012).

Namun, tidak ada definisi standar untuk pengawas syariah. Dari beberapa definisi tersebut dapat di simpulkan bahwa proses pengendalian, tinjauan dan analisis pencegahan, perbaikan dan pelengkap dari semua aktivitas, produk, kontrak, dan transaksi IFI (Islamic Financial Institution) mulai dari pendirian IFI (Islamic Financial Institution) dan seterusnya untuk memastikan kepatuhan dengan Syariah Islam untuk tujuan menghasilkan keuntungan yang sah (halal) dan peningkatan kinerja IFI (Islamic Financial Institution).

Persyaratak diangkatnya seseorang menjadi Anggota DPS harus memenuhi kriteria sesuai dengan POJK Nomor 3/POJK.30/2016, antara lain sebagai berikut (Keuangan, 2018):

56 | Analisis Kinerja Dewan Pengawas Syariah dalam Mengawasi Bank Syariah 
a. Integritas, yang paling sedikit mencakup:

1) Memiliki akhlak dan moral yang baik

2) Memiliki komitmen untuk mematuhi peraturan perbankan syariah dan peraturan perundang-undangan

3) Memiliki komitmen yang tinggi terhadap pengembangan operasional BPRS yang sehat

4) Tidak termasuk dalam DTL sebagaimana diatur dalam ketentuan Otoritas Jasa Keuangan mengenai uji kemampuan dan kepatutan bagi Bank Syariah dan Unit Usaha Syariah.

b. Kompetensi, yang paling sedikit memiliki pengetahuan dan pengalaman di bidang syariah mu'amalah dan pengetahuan di bidang perbankan dan/atau keuangan secara umam

c. Reputasi keuangan, yang paling sedikit mencakup

1) Tidak termasuk dalam daftar kredit macet

2) Tidak pernah dinyatakan pailit atau menjadi pemegang saham, anggota Direksi atau anggota Dewan Komisaris yang dinyatakan pailit, dalam waktu 5 tahun terakhir sebelum dicalonkan.

Adapun mekanisme kerja DPS, sebagaimana tertera dalam Pedoman Dasar DSN, yaitu sebagai berikut (Keuangan, 2018; Nizar, 2015):

a. Melakukan pengawasan secara periodik pada lembaga keuangan syariah yang berada di bawah pengawasannya.

b. Berkewajiban mengajukan usul-usul pengembangan lembaga keuangan syariah kepada pempinan lembaga yang bersangkutan dan kepada Dewan Pengawas Syariah Nasional.

c. Melaporkan perkembangan produk dan operasional lembaga keuangan syariah yang diawasinya kepada DSN sekurang-kurangnya dua kali dalam satu tahun anggaran.

d. Merumuskan permasalahan-permasalahan yang memerlukan pembahasan DSN.

Struktur Dewan Penagawas Syariah Nasional (DPS) adalah sebagai berikut (Jumadi, 2013):

a. DPS dalam struktur perusahaan berada setingkat dengan fungsi komisaris sebagai pengawas Direksi.

b. Jika fungsi komisaris adalah pengawas dalam kaitan dengan kinerja manajemen, maka DPS melakukan pengawasan kepada manajemen, dalam kaitan dengan implementsi sistem dan produk-produk agar tetap sesuai dengan prinsip syariah.

c. Bertanggung jawab atas pembinaan akhlak seluruh karyawan berdasarkan sistem pembinaan ke-Islaman yang telah diprogramkan setiap tahunnya.

d. Ikut mengawasi pelanggaran nilai-nilai Islam di lingkungan perusahaan tersebut.

e. Bertanggung jawab atas seleksi syariah karyawan baru yang dilaksanakan oleh Biro Syariah. 
Sedangkan kedudukan Dewan Pengawas Syariah (DPS) sebagaimana tercantum dalam buku yang diterbitkan oleh Bank Indonesia dijelaskan bahwa DPS mempunyai tiga kedudukan, yaitu sebagai berikut:

a. Sebagai penasihat dan pemberi saran kepada direksi, pimpinan Unit Usaha Syariah, dan pimpinan cabang syariah mengenai hal-hal yang berkaitan dengan aspek syariah.

b. Sebagai mediator antara bank dengan DSN dalam mengomunikasikan usul dan saran pengembangan produk dan jasa bank yang memerlukan kajian dan fatwa dari DSN.

c. Sebagai perwakilan DSN yang ditempatkan pada bank. DPS wajib melaporkan kegiatan usaha dan perkembangan bank syariah yang diawasinya kepada DSN atau satu kali dalam satu tahun (minimal).

d. Perlu ditambahkan bahwa kedudukan DPS di bank-bank syariah juga berkedudukan sebagai penjamin bahwa bank yang diawasinya berjalan sesuai dengan prinsip syariah.

\section{Metode}

\section{Pendekatan dan Jenis Pendekatan}

Mengenai metode Penelitian yang digunakan adalah deskriptif analisis. Metode deskriptif adalah suatu metode Penelitian yang berusaha untuk memperoleh informasi tentang gambaran keadaan pada saat Penelitian, kemudian dianalisis dan berusaha menjelaskan berdasarkan fakta-fakta atau kenyataan yang ada di lapangan (Aisyah, 2016).

Dalam Penelitian ini menggunakan pendekatan kualitatif, maksudnya Penelitian yang didasarkan pada latar alamiah sebagai sumber data langsung dan peneliti merupakan instrument kunci. Sebagaimana yang dijelaskan oleh Lexy J. Moleong bahwa Penelitian kualitatif adalah prosedur penelitian yang menghasilkan data deskriptif berupa kata-kata yang tertulis atau lisan dari orang-orang dan perilaku yang dapat dialami (Lexy, 2010).

\section{Teknik Analisis Data}

Analisi data pada penelitian kualitatif mengunakan teknik analisis induktif. Analisis data induktif menurut paradigma naturalistik adalah analisis data spesifik dari lapangan menjadi unit-unit dilanjutkan dengan kategori (Pratama, 2013). Analisis data merupakan penguraian teori-teori yang telah ditentukan sebelumnya yaitu, mengamati kinerja pengawasan Dewan Pengawas Syariah dari berbagai sumber rujukan, sehingga data yang dianalisis dapat memberi gambaran yang jelas tentang hasil pengamatan, juga mempermudah peneliti untuk mencari kembali data yang diperoleh apabila diperlukan.

Agar dapat dipahami maka semua data yang peneliti peroleh diolah sebagai berikut: 
a. Reduksi data

Reduksi data adalah proses pemusatan atau menonjolkan pokok-pokok yang penting, serta menyederhanakan, memfokuskan data mentah yang diperoleh dari lapangan dengan metode sedemikian rupa hingga kesimpulan-kesimpulan akhirnya dapat ditarik kesimpulan (Sugiyono, 2017).

b. Penyajian data

Proses penyusunan informasi kompleks yang diperoleh dari wawancara yang dilakukan, yang sistematis agar lebih sederhana dan melihat gambaran keseluruhan (Sugiyono, 2017).

c. Mengambil Kesimpulan

Data yang telah diperoleh dan telah dianalisis kemudian menarik makna dari analisis tersebut dengan membuat kesimpulan dan verifikasi yang jelas tentang kinerja pengawasan Dewan Pengawas Syariah di BPRS Bumi Rinjani Kepanjen.

\section{Hasil dan Pembahasan}

\section{Analisis Posisi Dewan Pengawas Syariah dalam Pengawasan Produk-Produk di BPRS Bumi Rinjani Kepanjen}

DPS adalah singkatan dari Dewan Pengawas Syariah, yang dibentuk oleh Majelis Ulama Indonesia (MUI) yang bertugas dan berwenang untuk menetapkan fatwa tentang produk dan jasa dalam kegiatan usaha bank untuk melaksanakan kegiatan usaha berdasarkan prinsip-prinsip syariah (Misbach, 2014). DPS terdiri dari pakar syariah yang mengawasi aktivitas dan operasional institusi finansial untuk memastikan kepatuhan terhadap prinsip-prinsip syariah(Nasution, 2018). DPS tidak hanya dapat mengerti dalam hal fiqih muamala saja, tetapi juga ilmu dalam hal finansial. Mereka dituntut untuk bisa menjadi panutan dalam hal kesyariahan suatu produk, dan tidak hanya produk yang menjadi obyek pengawasan.

Produk-produk yang ditawarkan di BPRS Bumi Rinjani Kepanjen beraneka ragam, diantaranya:

a. Simpanan:

1) Tabungan Mitra iB BSR

2) Tabungan Ribjani iB BSR

3) Tabungan Qurban iB BSR

4) Tabungan Aqiqah iB BSR

5) Tabungan Umroh Maqbulah iB BSR

6) Deposito Mudharabah

b. Penyaluran dana:

1) Musyarakah iB BSR

2) Mudharabah iB BSR

3) Murabahah iB BSR

4) Ijarah Multijasa iB BSR 
Di antara produk tersebut, produk yang mendominasi adalah produk dalam penyaluran dana yaitu Murabahah, sedangkan dalam Simpanan masih dalam kriteria seimbang tidak ada yang mendominasi.

Posisi DPS dalam hal pengawasan terhadap produk sesuai dengan amanah undang-undang dan peraturan OJK khususnya POJK Nomor 3/POJK.03/2016 tentang BPRS. DPS bertugas dan bertanggung jawab memberikan nasihat dan saran kepada Direksi serta mengawasi penerapan Prinsip Syariah dalam penghimpunan dana, pembiayaan dan kegiatan jasa BPRS. Salah satunya adalah melakukan kontroling, yaitu memastikan bahwa produk-produk yang diluncurkan oleh BPRS Bumi Rinjani Kepanjen sesuai dengan fatwa DSN.

Posisi DPS di BPRS Bumi Rinjani Kepanjen dari segi struktur organisasi adalah sejajar dengan direksi, dimana garisnya sejajar. Garis tersebut adalah garis komunikasi, sehingga DPS bisa memberi masukan terhadap pelaksanaan operasional, produk dan yang berkenaan dengan BPRS Bumi Rinjani Kepanjen.

Tugas DPS BPRS Bumi Rinjani Kepanjen adalah mengawal fatwa DSN-MUI untuk diterapkan langsung dalam BPRS tersebut, agar pelaksanaan akad di BPRS Bumi Rinjani Kepanjen sesuai dengan prinsip syariah. Dalam pelaksanaan tugasnya, DPS BPRS Bumi Rinjani Kepanjen membuat laporan hasil pengawasan baik produk penghimpunan maupun produk pembiayaan yang dilaporkan setiap 6 bulan sekali kepada OJK. Adapun laporan dilakukan dalam bentuk tertulis yaitu yang berkaitan dengan transaksi dan produknya.

DPS di BPRS Bumi Rinjani Kepanjen minimal satu kali dalam sebulan datang menuju kantor pusat untuk melakukan pengawasan karena selama ini masih dalam hal sistem yang di awasi di BPRS Bumi Rinjani Kepanjen. Pelaksanaan produk yang dipraktekkan di lapangan kadang tidak sesuai dengan sistem yang sudah dirancang oleh DPS di kantor pusat. Hal tersebut dikarenakan adanya perbedaan konsep antara yang menjalankan produk dengan sistem yang sudah dirancang, karena memang pengawasan untuk ke bawah masih belum begitu efektif. Akan tetapi, DPS di BPRS Bumi Rinjani Kepanjen mengizinkan, membolehkan, mengawasi dan memantau sesuai dengan syariah atau tidak, dan direksi yang melaksanakan, sedangkan komisaris mengarahkan, menganjurkan dan melihat perkembangannya.

Pelaksanaan pengawasan di BPRS Bumi Rinjani Kepanjen masih bisa tercover hanya dengan satu ketua dan satu anggota karena cakupannya masih kecil, dimana BPRS Bumi Rinjani Kepanjen mempunyai 1 kantor pusat dan 2 kantor cabang.

\section{Analisis Pengawasan Praktek Produk yang di Terbitkan oleh BPRS Bumi Rinjani Kepanjen}

Berdasarkan Keputusan DSN-MUI No.3 Tahun 2000 tentang petunjuk Pelaksanaan Penetapan Anggota Dewan Pengawas Syariah pada Lembaga Keuangan Syariah, syarat yang harus dimiliki oleh anggota DPS adalah sebagai berikut:

a. Memiliki akhlaq karimah. 
b. Memiliki kompetensi kepakaran di bidang syariah muamalah dan pengetahuan di bidang perbankan dan/atau keuangan secara umum.

c. Memiliki kelayakan sebagai pengawas syariah, yang dibuktikan dengan surat/sertifikat dari DSN.

Seluruh DPS di BPRS Bumi Rinjani Kepanjen sudah tersertifikasi sebagai salah satu syarat, karena dalam pengawasan terhadap produk harus menguasai fatwafatwa yang dikeluarkan oleh DSN. Tugas DPS betul-betul memastikan dari segi opini. Opini ini terjadi ketika suatu lembaga keuangan mengeluarkan produk baru.

Esensinya, DPS membuat opini syariah terkait produk-produk yang dijalankan Bank Syariah. Opini syariah yang dikeluarkan mengikat pada pendapat DPS perihal tingkat kesyariahan suatu transaksi bisnis, yang berkaitan dengan produk BPRS Bumi Rinjani Kepanjen.

Opini syariah dikeluarkan setelah kajian guna keberlanjutan akad. Dalam kajiannya, DPS bertugas memberi pertimbangan dengan mengkaji fatwa, dan dasardasar syariah sebelum diimplementasikan pihak bank. Hal-hal yang berkaitan dengan penerapan produk pada BPRS Bumi Rinjani Kepanjen dibahas pada rapat direksi maupun rapat khusus Dewan Pengawas Syariah. Rapat ini dilangsungkan minimal sekali dalam sebulan. Berikut mekanisme pengajuan opini syariah:

a. Bank mengajukan rancangan produk ke DPS untuk dipelajari dan dianalisa produk yang dikeluarkan bank syariah.

b. DPS mengadakan rapat internal untuk membahas boleh tidaknya akad dilanjutkan, dengan sejumlah rekomendasi yang harus dijalankan baik nasabah maupun pihak bank.

c. Rapat internal sekaligus pengesahan terhadap opini syariah yang dikeluarkan DPS.

d. Bank Syariah menjalankan produknya berdasarkan rekomendasi DPS.

Berdasarkan hasil dari data-data dilapangan. BPRS Bumi Rinjani Kepanjen dalam waktu dekat akan mengeluarkan 3 produk baru, diantaranya adalah:

a. Musyarakah Mutanaqishah

MMQ adalah kerjasama/perserikatan modal antara dua pihak yaitu bank dan nasabah untuk kepemilikan suatu barang secara bersama, dimana porsi kepemilikan salah satu pihak atas barang akan berkurang disebabkan pembelian secara bertahap oleh pihak lain.

b. Tabarok (Pembiayaan Tanpa Angunan Barokah)

Pembiayaan ini adalah tanpa anggunan yang diberikan secara khusus hanya pada BPRS Bumi Rinjani Kepanjen. Istilahnya adalah suatu hadiah yang diberikan kepada karyawan untuk memiliki asset perusahaan.

c. IMBT (Ijarah Muntahiya Bittamlik)

Kepemilikan suatu manfaat/jasa berupa barang yang jelas dalam tempo waktu yang jelas diikuti dengan adanya pemberian kepemilikan suatu barang yang bersifat khusus dengan adanya ganti yang jelas. 
Tiga produk ini adalah produk yang segera diluncurkan di BPRS Bumi Rinjani Kepanjen. Tugas DPS tak sebatas mengeluarkan opini syariah yang kemudian dijalankan BPRS Bumi Rinjani Kepanjen saja. Tidak juga lepas tangan saat produk yang disepakati telah dijalankan.

\section{Analisis Efektifitas Pengawasan Dewan Pengawas Syariah terhadap Seluruh Produk Perbankan yang ada di BPRS Bumi Rinjani Kepanjen}

Hidayat menyebut efektifitas sebagai ukuran yang menyatakan seberapa jauh target (kuantitas, kualitas, dan waktu) telah tercapai, dimana makin besar presentase target yang dicapai, makin tinggi juga efektifitasnya. Siagian (2011) juga berpendapat jika efektifitas menunjukan keberhasilan dari segi tercapai tidaknya sasaran yang telah ditetapkan, semakin tinggi mendekati sasaran maka makin tinggi juga efektifitasnya.

Dengan kata lain, efektifitas menjadi tolak ukur dalam menilai kinerja seseorang, atau kelompok tertentu. Efektifitas dapat dinilai berdasarkan target dan standar kerja yang ditetapkan apakah tercapai selama bekerja. Semakin sedikit target yang tercapai maka semakin rendah pula efektifitasnya. DPS yang ditunjuk langsung oleh Bank Indonesia sebagai badan pengawas resmi di BPRS Bumi Rinjani Kepanjen.

Konsep lain yang dapat digunakan dalam mengukur kinerja ialah efektifitas dan efisiensi. Dimana efektifitas berarti mengerjakan sesuatu yang besar, sedangkan efisiensi mengerjakan sesuatu dengan benar. Dengan kata lain, efektifitas menjadi tolak ukur dalam menilai kinerja seseorang, atau kelompok tertentu. Efektifitas dapat dinilai berdasarkan target dan standar kerja yang ditetapkan apakah tercapai selama bekerja. Semakin sedikit target yang tercapai maka semakin rendah pula efektifitasnya. DPS yang ditunjuk langsung oleh Bank Indonesia sebagai badan pengawas resmi di BPRS Bumi Rinjani Kepanjen.

Dalam regulasinya, DSN menerangkan perihal tugas pokok DPS di antaranya, mengawasi secara periodik pada lembaga keuangan syariah, mengajukan usul-usul lembaga keuangan syariah kepada pimpinan terkait dan DSN, melaporkan perkembangan produk dan operasional lembaga keuangan sekurang-kurangnya dua kali dalam satu tahun anggaran, serta merumuskan permasalahan yang memerlukan pembahasan DSN (Zandra, 2016).

Laporan DPS, berisi perkembangan-perkembangan baru dalam aktivitas usaha perusahaan, dibuat penyampaian hasil-hasil opini, dan bisa juga berupa pendapat ulama dan usulan-usulan DPS perihal akad baru.

Menurut Pak Imam Mudzakir selaku ketua DPS di BPRS Bumi Rinjani Kepanjen, prestasi yang di dapat adalah BPRS Bumi Rinjani Kepanjen termasuk lembaga keuangan yang terpaling bagus di wilayah OJK Malang, karena dari sisi target yang dibuat/dilaporkan terpenuhi. Serta kwalitas pembiayaan cukup bagus dan DPS juga menjadi salah satu kontributor serta editor untuk buku literasi keuangan yang diperuntukkan untuk generasi muda.

Pencapaian yang demikian menjadi satu dari bukti efektifnya kinerja DPS membawa perusahaan mampu dinilai sebagai lembaga keuangan yang terpaling bagus 
di wilayah OJK Malang. Sesuai sistem pengawasan dimana belum ditemukannya pelanggaran selama 14 tahun berdiri, menjadi bukti kinerja lain DPS yang patuh terhadap berbagai regulasi yang mengikat, baik syariat Islam, pemerintah maupun perusahaan itu sendiri.

Pada dasarnya, DPS tidak menetapkan target kerja selayaknya karyawan atau pimpinan, soal pendanaan juga prestasi. Melainkan dengan berpegang teguh pada kepatuhan syariah (Syariah Complaince) yaitu POJK Nomor 3/POJK. 03/2016 tentang Bank Pembiayaan Rakyat Syariah, dan memastikan bank syariah berjalan pada lininya adalah pencapaian yang terus dipertahankan

Kinerja DPS efektif, karena menjalankan tugas dan tanggung jawab sesuai dengan POJK Nomor 3/POJK. 03/2016 tentang Bank Pembiayaan Rakyat Syariah. Bukti efetifitas DPS BPRS Bumi Rinjani Kepanjen adalah dengan mengawasi proses pengembangan produk baru, melakukan tinjauan secara berkala terhadap mekanisme penghimpunan dana dan penyaluran dana serta pelayanan jasa, mengerjakan laporan dengan meminta data dan informasi terkait dengan aspek syariah dari satuan kerja di BPRS, dan selalu memberi saran kepada direksi, pimpinan mengenai hal-hal yang terkait dengan aspek syariah, namun penulis juga menemukan sejumlah kelemahan, walaupun tidak melanggar regulasi tapi penting diperbaiki agar perkembangan kinerja yang lebih baik.

Meski tidak melanggar aturan, namun keterbatasan pengawasan di sejumlah kantor cabang tidak bisa menjamin sepenuhnya pelanggaran yang bisa saja terjadi. Terlebih, kehalalan produk bank syariah tergantung pada kontrol DPS yang maksimal.

\section{E. Kesimpulan}

Kinerja DPS di BPRS Bumi Rinjani Kepanjen terbilang efektif. Tugas DPS yang dibebankan DSN seperti pengawasan periodik, mengajukan usul lembaga, melaporkan perkembangan produk, dan merumuskan permasalahan telah dijalankan dengan baik. Serta dalam periode ini dapat meluncurkan tiga produk baru. Secara operasional dan pengawasan serta praktek terhadap produk terbilang efektif. Sesuai dengan tugas dan tanggung jawab yang harus dilaksanakan oleh DPS yang ada pada POJK Nomor

3/POJK.03/2016 tentang Bank Pembiayaan Rakyat Syariah, karena hanya masih mengawasi dua kantor cabang yang memungkinkan dapat dengan mudah dijangkau oleh 2 DPS. Tidak dapat dibuat patokan untuk bank-bank yang sudah berskala nasional yang cabangnya lebih dari dua dan tersebar di seluruh wilayah Indonesia. 


\section{DAFTAR PUSTAKA}

Garas, S. N., \& Pierce, C. (2010). Shari'a supervision of Islamic financial institutions. Journal of Financial Regulation and Compliance, 18(4), 386-407.

Heteronom, P. (2017). Peran Dewan Pengawas Syariah Terhadap Syariah Compliance Pada Perbankan Syariah. Jurnal Surya Kencana Satu: Dinamika Masalah Hukum Dan Keadilan, 8(2), 49-61.

Ismanto, D., \& Laksono, D. K. A. (2020). Analisis Perbandingan Kinerja Keuangan pada Bank Umum Syariah BUMN (Bank BRI Syariah, Bank Syariah Mandiri dan Bank BNI Syariah). Jurnal Pasar Modal Dan Bisnis, 2(2), 99-114.

Jumadi, J. (2013). Analisis Ekonomi Islam Terhadap Bagi Hasil Pembiayaan Mudharabah Untuk Usaha Mikro Pada Baitul Qiradh Abu Indrapuri. Share: Jurnal Ekonomi Dan Keuangan Islam, 2(1).

Keuangan, O. J. (2018). Prinsip dan Konsep Dasar Perbankan Syariah. Otoritas Jasa Keuangan.

Kurrohman, T.-. (2017). Peran Dewan Pengawas Syariah Terhadap Syariah Compliance Pada Perbankan Syariah. Jurnal Surya Kencana Satu: Dinamika Masalah Hukum Dan Keadilan, 8(2), 49.

Lexy, J. (2010). Moleong. Metodologi Penelitian Kualitatif, 163.

MA Pratama. (2013). Metodelogi Penelitian Kualitatif, Teknik Pengumpulan Data. Journal of Chemical Information and Modeling, 53(9), 1689-1699.

Misbach, I. (2014). Kedudukan dan Fungsi Dewan Pengawas Syariah dalam Mengawasi Transaksi Lembaga Keuangan Syariah di Indonesia. Fakultas Dakwah Dan Komunikasi UIN Alauddin Makassar, 79-93.

Nasution, I. I. (2018). Peran Dewan Pengawas Syariah ( DPS ) dalam Perusahaan Investasi Berbasis Syariah. Master Thesis, 106.

Nathan Garas, S. (2012). The control of the Shari'a Supervisory Board in the Islamic financial institutions. International Journal of Islamic and Middle Eastern Finance and Management, 5(1), 8-24.

Nawangsari, R. D., \& Ika Nugroho, P. (2019). Pengaruh Indikator Kinerja Ekonomi, Indikator Kinerja Lingkungan dan Indikator Kinerja Sosial terhadap Profitabilitas Perusahaan Manufaktur. International Journal of Social Science and Business, 3(2), 162.

Nizar, M. (2015). Implementasi Pembiayaan Murabahah Dalam Meningkatkan Profitabilitas. An-Nisbah: Jurnal Ekonomi Syariah, 2(1).

Nizar, M. (2016). Proses Entrepreneurship, Kolaborasi Inovasi, Penciptaan Kekayaan Di Dalam Organisasi Bisnis (Studi Mikro Bank Syari'ah Universitas Yudharta Purwosari Pasuruan). Jurnal Hukum Islam, Ekonomi Dan Bisnis, 2(9), 91-103.

Oktiani, N., Sabariah, E., Saridawati, S., \& Caroline, P. (2019). Implementasi Penerapan Motivasi Kerja dan Kinerja Karyawan Terhadap Peningkatan Produktifitas Kerja. Widya Cipta: Jurnal Sekretari Dan Manajemen, 3(2), 255-262. 
Otoritas Jasa Keuangan. (2019). Siaran Pers Survei OJK 2019: Indeks Literasi Dan Inklusi Keuangan Meningkat. In SP 58/DHMS/OJK/XI/2019 (Issue November).

Robbins, S. P., \& Judge, T. A. (2008). Perilaku Organisasi Jilid II. Salemba Empat.

Rosyidah, Nizar, M., \& Khoirul Huda. (2019). Analisis Pengetahuan Nasabah Tentang Produk Perbankan Syariah (Studi pada Bank Muamalat KCP Malang Kepanjen). MALIA (Terakreditasi), 10(2), 163-180.

S, A. (2016). Metodologi Penelitian: Pendekatan Penelitian. Artikel, 33-40.

Siagian, N., \& Siregar, T. H. S. (2011). Pemeriksaan kualitas sadapan untuk mendukung produktivitas yang tinggi. Warta Perkaretan, 30(11), 26-33.

Sugiyono. (2017). Metode Penelitian Bisnis (Pendekatan Kuantitatif, Kualitatif, Kombinasi dan R\&D). In Metodelogi Penelitian (p. 2).

Zandra, R. A. P. (2016). Efektivitas Pengawasan Dewan Pengawas Syariah (DPS) Terhadap Operasional Bank Syariah. Aktiva Jurnal Akuntansi Dan Investasi, 1(2), 158-174. 
..:: Malia: Jurnal Ekonomi Islam Vol. 12 No. 1, Desember 2020 ::.. 